\title{
IS IT GOOD TO BE RESILIENT DURING THE COVID-19 PERIOD? THE ROLE OF EGO-RESILIENCY IN THE INTENSITY OF SYMPTOMS OF ANXIETY, ALCOHOL USE AND AGGRESSION AMONG POLISH PEOPLE
}

\section{PAWEŁ DĘBSKI, SZYMON FLOREK, MAGDALENA PIEGZA, ROBERT PUDLO, and PIOTR GORCZYCA}

Medical University of Silesia, Katowice, Poland

Faculty of Medical Sciences in Zabrze, Department of Psychiatry

\begin{abstract}
Objectives: The SARS-CoV-2 pandemic has affected the development of negative phenomena such as anxiety symptoms, a tendency to use alcohol and aggressive behaviors. It is postulated to investigate the factors limiting the development of the indicated adverse effects. One of the psychological resources that may have a significant, pro-health character in relation to mental functioning is ego-resiliency (ER). It is described as a personality trait associated with a high ability to adequately regulate self-control, depending on the conditions. There are studies providing information about the prohealth, adaptive nature of ER during the COVID-19 period. The aim of the study was to assess the relationships between ER and anxiety, the tendency to use alcohol and aggression in the group of Polish people in the initial lockdown period in Poland. Material and Methods: Overall, 538 adult Polish people participated in the study. The Ego-Resiliency Scale referred to as ER89-R12, according to Block's concept, was used to measure ER. The other scales used were the General Anxiety Disorder Scale, the Alcohol Use Disorder Identification Test, and the Buss-Perry Aggression Questionnaire. Statistical analyses were performed using Spearman's rank correlation coefficient, the multiple regression procedure, the Mann-Whitney U test and the Kruskal-Wallis rank ANOVA. Cronbach's $\alpha$ coefficients were also assessed. Results: Statistically significant negative relationships between ER and the severity of anxiety symptoms and generalized aggression were found. There was a weak positive relationship between ER and the tendency to use alcohol. Among the surveyed Polish people, higher ER was characteristic of the older respondents (aged >29 years) and people with higher education. Conclusions: Ego-resiliency in the times of the SARS-CoV-2 pandemic can counteract the development of anxiety and aggression. Optimal regulation seems to play an important role in this relationship. The relationship between resiliency and the tendency to use alcohol requires further observation. Int J Occup Med Environ Health. 2021;34(2):289-300
\end{abstract}

Key words:

alcohol, resiliency, anxiety, aggression, COVID-19, pandemic

\section{INTRODUCTION}

The first case of SARS-CoV-2 infection in Poland was confirmed on March 4, 2020. By the end of April 2020, when the presented study was conducted, the number of infection cases had exceeded 10000 with nearly 500 re- corded deaths. The SARS-CoV-2 pandemic has been associated with numerous challenges for the functioning of social systems at every level of their organization. During the fight against the pandemic, the existing civil liberties were limited. In the initial phase of the virus spreading,

Received: October 26, 2020. Accepted: April 26, 2021

Corresponding author: Paweł Dębski, Medical University of Silesia, Faculty of Medical Sciences in Zabrze, Department of Psychiatry, Pyskowicka 49, 42-612 Tarnowskie Góry, Poland (e-mail: pdebski@sum.edu.pl). 
people had to confront previously unknown situations. There was a common fear of being infected with the virus which could cause unpredictable health consequences. The fear of the virus also included concerns for the health of one's relatives. The pandemic has become the dominant theme presented by the media with regular reports on further infections, hospitalizations and the number of deaths related to the virus. The pandemic has forced numerous changes, such as the reorganization of healthcare, work, education and even judiciary systems. The necessity to suddenly adapt to new living conditions in many basic fields was associated with an increase in people's emotional tension.

Pandemic stress has appeared to negatively affect the mental functioning of individuals. It may contribute to the intensification of anxiety, depression, as well as to the occurrence of socially unacceptable tendencies, such as excessive alcohol consumption and aggressive behaviors. A widespread increase in anxiety tension has been clearly indicated in research analyzing the psychological situation of citizens during the pandemic period [1,2]. Similarly, the increase in alcohol consumption has been observed in some social groups [3,4]. The emotional tension related to the pandemic also seems to take part in the development of aggressive tendencies, the increase in which has been described in various parts of the world $[5,6]$. There is no doubt that the pandemic is conducive to the development of mental disorders and social pathologies. That observation prompted the authors of this article to look for protective factors that could help in coping with crisis and support flexible adaptation to changing life conditions. One such psychological factor is ego-resiliency (ER).

Research on ER and its negative links with anxiety and other maladaptive psychological consequences of COVID-19 has been postulated in the literature since the beginning of the pandemic [7]. Resiliency is a healthpromoting (salutogenetic) psychological characteristic which plays a homeostatic role for the human psyche [8].
It has been indicated that ER is associated with effective functioning and adaptation [9]. Resiliency, in general, means the ability to cope well with difficult, crisis and challenging situations. In addition, ER can be considered from a processual or personality perspective [10]. From the personality perspective, resiliency is described as a trait or a stable disposition for behavior, which supports good dealing with crises. Ego-resiliency is one of the major components of the affect processing system in Block's theory of personality. It is considered to be the metatrait responsible for the flexibility and adaptability of the entire personality [11]. Block [12,13] described ER as a high capacity for self-regulation. As a personality trait, ER is, therefore, based on the ability to adequately control stimuli, which allows for intensifying control or weakening it in justified circumstances.

The mechanism of resiliency is related to a person's ability to dynamically adjust the level of psychological control depending on the situational conditions. In other words, resiliency means the capacity to regulate the ego-control, which results in the inhibition or expression of impulses in a way appropriate to given circumstances. The proper management of the implementation of impulses should, in turn, support the undertaking of adaptive behavior. This ensures behavior flexibility in stressful situations. Resiliency supports the adequate coping with challenges and thus counteracts the development of anxiety and maladaptive pathological behavior. Meta-analyses conducted by Jeong and Kim [14] considered ER as a resource that helped maintain physical, psychological and social well-being in various adversities. In research by Allesandri et al. [15], resiliency turned out to be a factor weakening the influence of everyday stressors on the formation of emotional inertia.

The ability to adequately and dynamically adjust psychological control of impulses and thus undertake adaptive behavior seems to be extremely important in the times of rapidly changing pandemic conditions. The time of the pandemic is associated with many challenges and stressors 
such as job loss, quarantine, isolation, illness, hospitalization, post-COVID-19 complications and, finally, illness or death of the loved ones. Features of a resilient person, including the ability to deal flexibly through adequate control should help in coping with the numerous stressors of the pandemic. Research reports have been promoting resiliency as a trait, which is supportive for adaptability in the SARS-CoV-2 pandemic conditions [16,17]. Its antidepressant and anti-stress character has been indicated. What is more, ER has been shown to be a protective factor against the fear of COVID-19 among healthcare professionals [18], and against the novel coronavirus anxiety in general [19]. The pro-health effect of resiliency is also achieved in the times of COVID-19 by its participation in maintaining a sense of happiness [20]. However, there are no satisfactory reports on the role of ER in counteracting the development of anxiety and other maladaptive tendencies in Polish circumstances.

Ego-resiliency has been considered to consist of 2 components - optimal regulation (OR) and openness to life experiences (OL), recognized as personality traits [11,12]. Optimal regulation means the ability to stabilize psychological functioning. It is responsible for keeping the personality system in balance in the face of stressors and crisis situations. This means that OR plays a homeostatic role for the human psyche. Openness to life experiences, in turn, is responsible for flexible functioning, which supports adaptation to changing environmental conditions. More specifically, OL means the ability to skillfully engage in the functioning of the environment, which is associated with openness to the development of new experiences. This feature also contributes to adaptive response in dynamically changing conditions.

In their research, the authors decided to study the relationships between ER (OR and OL) and anxiety, propensity to use alcohol and aggression in the Polish cultural conditions during the initial period of the COVID-19 pandemic. The assessment of the influence of resiliency on the studied variables was also important for them. Moreover, they decided to check whether there were any significant differences in the intensity of ER in different sociodemographic subgroups. For this purpose, they compared, among others, groups of people with higher and secondary education. They decided to divide the study group in such a way for 2 reasons. The first reason was previous reports indicating that ER could be associated with better educational achievements [21]. The second reason was that the majority of the respondents were classified as people with higher or secondary education, which made it possible to compare only those groups.

Similar reasons for the division into comparative groups concern age. The authors decided to divide the study group by age, taking 29 years as the borderline value. Previous studies have suggested the increase in resiliency with age [22]. Changes in ER were noted mainly in relation to childhood and adolescence. Resiliency is said to be relatively stable after those periods [23]. Little research has been devoted to changes in resiliency in groups of adults. Taking into account the dynamic changes related to middle age, the study of ER in this group seems to be important. The proposed division made it possible to obtain 2 subgroups of similar sizes, representing, respectively, people in early adulthood and those in middle adulthood. It allowed for observing the intensification of ER in those 2 development groups.

The research corresponds to the exploratory scientific directions postulated in the world literature during the SARS$\mathrm{CoV}-2$ pandemic. It allowed for preliminary observations on the relationships of ER with negative psychological phenomena during the lockdown period in Poland.

\footnotetext{
Aim

The aim of the study was to determine the relationships between ER and the severity of anxiety, the tendency to use alcohol and aggression during the SARS-CoV-2 pandemic among the surveyed Polish people.
} 


\section{MATERIAL AND METHODS}

A total of 538 Polish people participated in the survey, including 413 women (76.77\%) and 125 men (23.23\%). The demographic characteristics of the study group are presented in Table 1.

The survey was conducted on April 24-May 8, 2020. It was made available via online means of communication in the initial lockdown period in Poland. Convenience sampling with the use of social media such as Facebook was a method of collecting the study group.

The University's Bioethics Committee approved the study design (decision No. PCN/0022/KB/76/20). Before

Table 1. Demographic characteristics of the study group of adult Polish people, April 24-May 8, 2020, Poland

\begin{tabular}{|c|c|c|}
\hline \multirow{2}{*}{ Variable } & \multicolumn{2}{|c|}{$\begin{array}{l}\text { Participants } \\
(\mathrm{N}=538)\end{array}$} \\
\hline & $\mathrm{n}$ & $\%$ \\
\hline \multicolumn{3}{|l|}{ Sex } \\
\hline $\operatorname{man}$ & 125 & 23.23 \\
\hline woman & 413 & 76.77 \\
\hline \multicolumn{3}{|l|}{ Age } \\
\hline $18-29$ years & 366 & 68.03 \\
\hline $30-49$ years & 147 & 27.32 \\
\hline $50-69$ years & 23 & 4.28 \\
\hline$\geq 70$ years & 2 & 0.37 \\
\hline \multicolumn{3}{|l|}{ Place of residence } \\
\hline village & 105 & 19.52 \\
\hline town $<50000$ inhabitants & 90 & 16.73 \\
\hline \multicolumn{3}{|l|}{ city } \\
\hline 50 000-200 000 inhabitants & 104 & 19.33 \\
\hline >200 000 inhabitants & 239 & 44.42 \\
\hline \multicolumn{3}{|l|}{ Education } \\
\hline primary & 7 & 1.30 \\
\hline vocational & 1 & 0.19 \\
\hline secondary & 254 & 47.21 \\
\hline higher & 271 & 50.37 \\
\hline no answer & 5 & 0.93 \\
\hline
\end{tabular}

joining the survey, information about its scientific purpose, as well as anonymous and voluntary nature, was provided. Each respondent could decide freely to pass the study or to stop completing the questionnaires at any time. The authors declare that there is no conflict of interest in connection with the study. The results presented in this paper are a part of a larger research project and illustrate some of the observations made in the first phase of the study.

Psychometric tests and popular screening tools were used as the research methods.

\section{Ego-Resiliency Scale}

The measurement of the level of ER was conducted using the Polish adaptation of the Ego-Resiliency Scale marked as ER89-R12. This tool is popular in international research and was developed by Block [12,13]. It is based on his concept of resiliency, in which ER is considered as a personality trait. The questionnaire consists of 12 questions. Answers are given on a 4-point scale. Four questions (Nos. 6-9) correspond to the OR subscale, and the remaining 8 questions to the OL subscale. The reliability of the tool in the test adaptation procedure measured with Cronbach's $\alpha$ coefficient was 0.80 - for the OR subscale 0.77 , and for the OL subscale 0.59 . Cronbach's $\alpha$ in this study was 0.81 for the general scale.

\section{Generalized Anxiety Disorder Scale}

The Generalized Anxiety Disorder Scale (GAD-7) is the scale developed by Spitzer et al. [24]. In the Polish language version, it contains 7 questions. For each of them, the respondent may receive $0-3$ pts. The scale result is the sum of the points obtained. The respondents refer to the questions, taking into account the last 2 weeks preceding the survey. The validity of the original test was assessed by examining the consistency of the results with the diagnoses of healthcare professionals. The original tool achieved satisfactory psychometric characteristics. 
Its sensitivity was $89 \%$ and specificity $82 \%$. Cronbach's $\alpha$ in this study was 0.87 .

\section{Alcohol Use Disorder Identification Test}

The Polish version of the international screening test the Alcohol Use Disorder Identification Test (AUDIT) was used to measure the tendency to abuse alcohol [25]. This questionnaire consists of 10 questions. Answers on a 5-point scale are allowed. In each question, it is possible to get $0-4$ pts. The total test score is obtained by adding up all the points indicated. Cronbach's $\alpha$ in this study was 0.79 .

\section{Buss-Perry Aggression Questionnaire}

This scale was originally designed by Buss and Perry [26]. The respondents were provided with the Polish version of this scale, adapted by the Amity Institute. It consists of 29 statements. Each of them is assessed on a 5-point Likert scale, within which it is possible to obtain 1-5 pts. The overall score is reached by adding the individual points together, taking into consideration 2 reversed scores. Generalized aggression consists of components such as physical aggression, verbal aggression, anger and hostility. The adaptive studies revealed the 4-factor structure of the scale. The stability of the subscales ranged $0.72-0.80$. Cronbach's $\alpha$ in this study was 0.88 for the general scale.

\section{Statistical analysis}

The collected data were analyzed with the use of Excel 2016 and Statistica v. 13.3. The assessment of the normality of distributions was made on the basis of the ShapiroWilk test. The correlation matrices were created using Spearman's rank correlation coefficient. Multiple regression models were also prepared to capture the role of ER components in the severity of anxiety, alcohol use and aggression. The study of the significance of intergroup differences was carried out using the Mann-Whitney U test and the Kruskal-Wallis rank ANOVA. The internal consistency of the applied tests was estimated using Cronbach's $\alpha$ coefficient. A significance level of $p<0.05$ was adopted in the statistical procedures.

\section{RESULTS}

The descriptive statistics of all variables are presented in Table 2. The study revealed significant correlations between ER, its components (OR and OL), and anxiety, the tendency to use alcohol and aggression. The relations are presented in Table 3.

Table 2. Descriptive statistics of the variables in the study group of adult Polish people ( $\mathrm{N}=538)$, April 24-May 8, 2020, Poland

\begin{tabular}{lcccc}
\hline \multicolumn{1}{c}{ Variable } & $\mathrm{M}$ & $\mathrm{SD}$ & $\mathrm{Me}$ & $95 \% \mathrm{CI}$ \\
\hline Ego-resiliency & 35.502 & 6.152 & 35.000 & $5.805-6.544$ \\
Optimal regulation & 23.214 & 4.435 & 23.000 & $4.185-4.717$ \\
Openness to life experiences & 12.288 & 2.618 & 13.000 & $2.470-2.785$ \\
Anxiety & 7.320 & 5.260 & 6.000 & $4.963-5.595$ \\
Alcohol & 4.210 & 4.004 & 3.000 & $3.778-4.259$ \\
Generalized aggression & 70.100 & 16.059 & 68.000 & $15.153-17.080$ \\
Physical aggression & 16.205 & 5.351 & 15.000 & $5.049-5.691$ \\
Verbal aggression & 14.593 & 3.682 & 14.000 & $3.474-3.916$ \\
Anger & 18.201 & 5.948 & 18.000 & $5.613-6.326$ \\
Hostility & 21.102 & 6.423 & 21.000 & $6.061-6.831$ \\
\hline
\end{tabular}


Table 3. Relationships between ego-resiliency and anxiety, the tendency to use alcohol and aggression in the study group of adult Polish people ( $\mathrm{N}=538)$, April 24-May 8, 2020, Poland

\begin{tabular}{|c|c|c|c|c|c|c|c|}
\hline \multirow{3}{*}{ Variable } & \multicolumn{7}{|c|}{ Spearman's correlation } \\
\hline & \multirow{2}{*}{ anxiety } & \multirow{2}{*}{ alcohol } & \multicolumn{3}{|c|}{ aggression } & \multirow{2}{*}{ anger } & \multirow{2}{*}{ hostility } \\
\hline & & & generalized & physical & verbal & & \\
\hline Ego-resiliency & $-0.118^{*}$ & $0.121^{*}$ & $-0.110^{*}$ & 0.018 & $0.157^{*}$ & -0.083 & $-0.299 *$ \\
\hline Optimal regulation & $-0.187^{*}$ & 0.083 & $-0.132 *$ & -0.008 & $0.180^{*}$ & $-0.110^{*}$ & $-0.319^{*}$ \\
\hline Openness to life experiences & 0.023 & $0.118^{*}$ & -0.023 & 0.071 & 0.069 & 0.004 & $-0.160^{*}$ \\
\hline
\end{tabular}

* Statistically significant at $\mathrm{p}<0.05$.

Table 4. The regression model of anxiety in the light of the components of ego-resiliency in the study group of adult Polish people $(\mathrm{N}=538)$, April 24-May 8, 2020, Poland

\begin{tabular}{|c|c|c|c|c|c|c|c|}
\hline Predictor & $b$ & b SE & $\beta$ & $\beta \mathrm{SE}$ & $\mathrm{t}$ & $\mathrm{p}$ & Model properties \\
\hline Anxiety & & & & & & & $\begin{aligned} \mathrm{R}^{2} \text { corr. } & =0.040, \mathrm{~F}(2.535)=12.441, \\
\mathrm{p} & <0.000, \mathrm{SEE}=5.151\end{aligned}$ \\
\hline constant & 10.508 & 1.304 & - & - & 8.059 & $0.000^{*}$ & \\
\hline optimal regulation & -0.285 & 0.057 & -0.240 & 0.048 & -4.962 & $0.000^{*}$ & \\
\hline openness to life experiences & 0.279 & 0.097 & 0.139 & 0.048 & 2.867 & $0.004^{*}$ & \\
\hline Tendency to use alcohol & & & & & & & $\begin{array}{c}\mathrm{R}^{2} \text { corr. }=0.011, \mathrm{~F}(2.535)=3.941 \\
\mathrm{p}\end{array}$ \\
\hline constant & 1.768 & 1.008 & - & - & 1.754 & 0.080 & \\
\hline optimal regulation & 0.015 & 0.044 & 0.016 & 0.049 & 0.333 & 0.739 & \\
\hline openness to life experiences & 0.171 & 0.075 & 0.112 & 0.049 & 2.270 & $0.024^{*}$ & \\
\hline Generalized aggression & & & & & & & $\begin{array}{c}\mathrm{R}^{2} \text { corr. }=0.017, \mathrm{~F}(2.535)=5.589 \\
\mathrm{p}<0.004, \mathrm{SEE}=15.923\end{array}$ \\
\hline constant & 78.197 & 4.030 & - & - & 19.401 & $0.000^{*}$ & \\
\hline optimal regulation & -0.593 & 0.178 & -0.164 & 0.049 & -3.342 & $0.001^{*}$ & \\
\hline openness to life experiences & 0.462 & 0.301 & 0.075 & 0.049 & 1.536 & 0.125 & \\
\hline
\end{tabular}

$\mathrm{R}^{2}$ corr. - corrected $\mathrm{R}^{2}$.

* Statistically significant at $\mathrm{p}<0.05$.

\section{Ego-resiliency and anxiety}

The significant differences that were obtained indicated that ER was negatively related to the severity of anxiety symptoms. The same nature of the relationship with anxiety was also noted in reference to OR (Table 3 ).

The regression analysis suggested that OR and OL could have an impact on the intensity of anxiety experienced by the respondents. More specifically, OL could be associ- ated with perceived anxiety, while OR could play a role in its decline. The model presenting these relationships is included in Table 4.

\section{Ego-resiliency and the tendency to use alcohol}

Generally, ER of the respondents was characterized by a weak positive relationship with the tendency to use alcohol. This association was also found with regard to OL (Table 3). 
It was revealed that OL might increase the tendency to use alcohol (Table 4).

\section{Ego-resiliency and aggression}

Global ER was negatively associated with generalized aggression and its component - hostility. A positive relationship was revealed between ER and verbal aggression while OR was negatively associated with generalized aggression as well as with hostility and anger. On the other hand, a positive relationship was found between OR and verbal aggression while OL was negatively associated with hostility (Table 3).

The regression analysis also showed that $\mathrm{OR}$ might reduce the level of generalized aggression (Table 4).

\section{Differences in the respondents' ER}

It was found that ER did not differ significantly depending on the respondents' sex. There were also no significant differentiations with regard to the place of residence and the assessment of employment stability made by the subjects.

The comparative analysis showed statistically significant differences in the results obtained for ER in general, and for its both subscales (OR and OL), between younger ( $\leq 29$ years) and older (>29 years) people (Table 5). The older age group was characterized by a significantly higher resiliency (Figure 1).

Similarly, significant differences in terms of ER and its subscales were noted in relation to the respondents' education (Table 5). The results of people with higher and secondary education were compared. The subjects with tertiary education were characterized by significantly higher resiliency (Figure 1).

\section{DISCUSSION}

\section{Ego-resiliency and anxiety}

Ego-resiliency as a salutogenetic property with an established, pro-health character [8] should counteract the de-

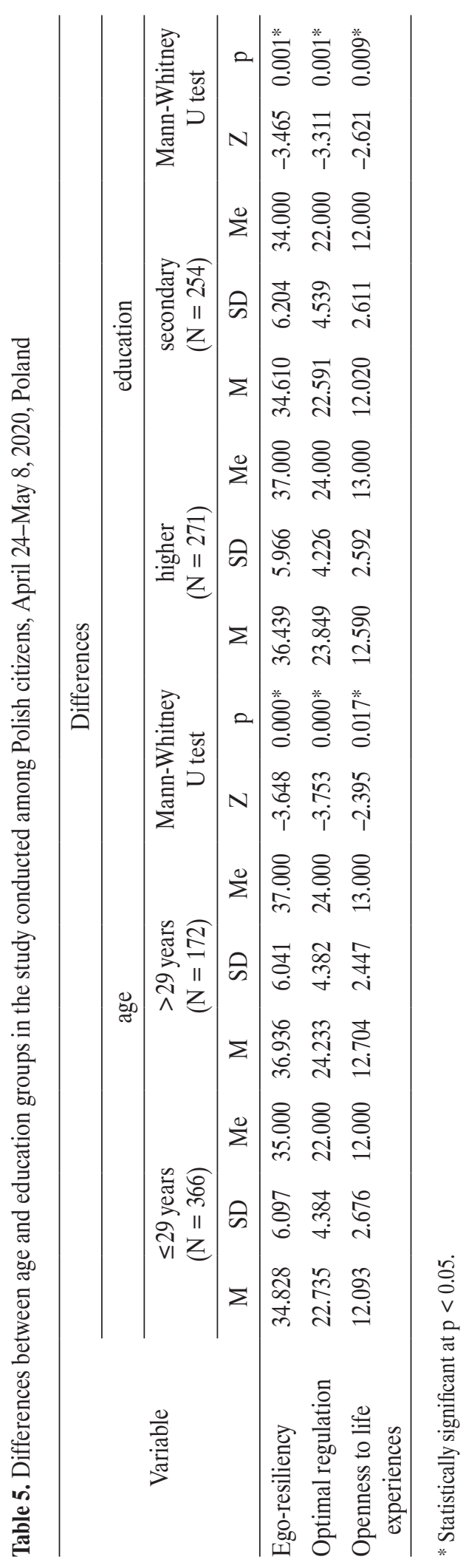



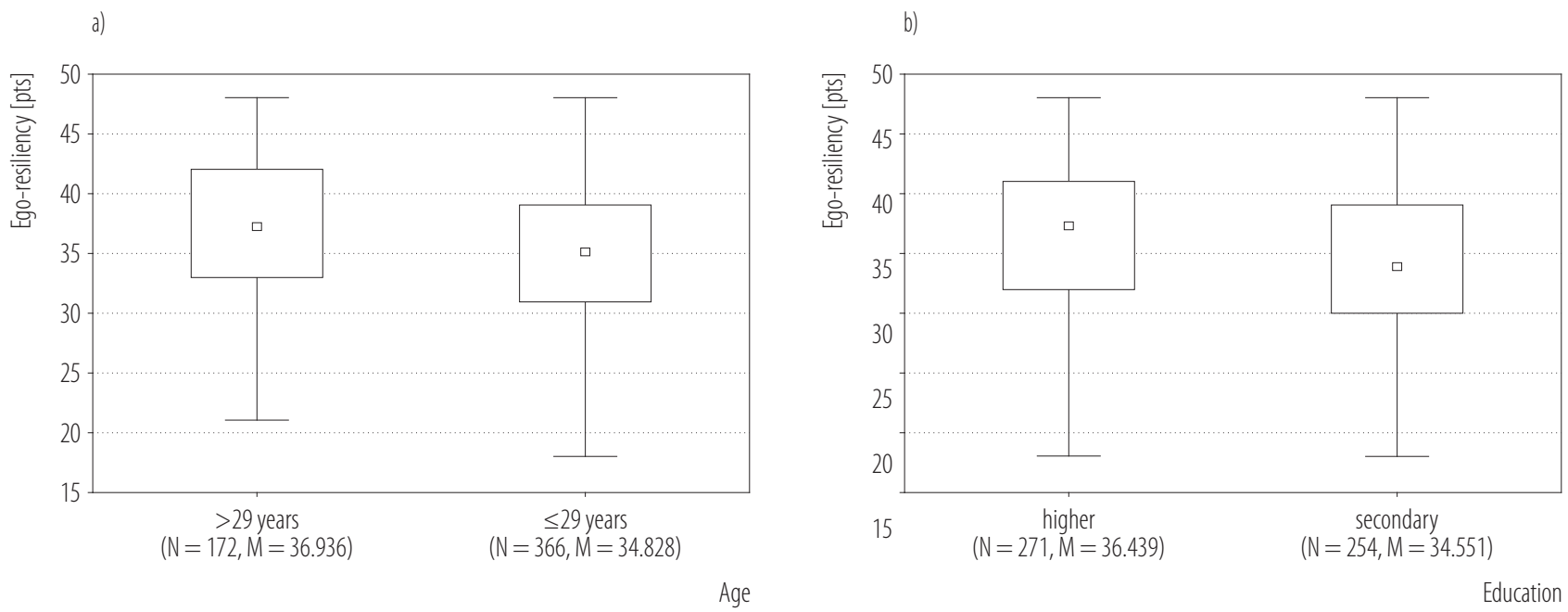

Figure 1. Comparison of ego-resiliency depending on the a) age of the respondents, b) education of the respondents, in the study conducted among Polish citizens, April 24-May 8, 2020, Poland

velopment of anxiety by supporting good coping with crisis situations, e.g., related to the SARS-CoV-2 pandemic.

The obtained results confirmed the negative relationship characterizing general ER and anxiety in the times of the SARS-CoV-2 pandemic. The ability for optimal mental regulation seems to play a special role here. The increase in this component of resiliency may take part in reducing anxiety tension. Good psychological regulation consisting in a balanced level of control, adapted to the situation, allows for an adequate response to dynamically changing conditions. Notably, OR supports task-based dealing with crises, which at the same time should lower and inhibit the anxiety developed in situations of uncertainty related to the anticipation of the effects of a crisis (e.g., an illness, a disease of one's relatives, isolation, quarantine). The negative relationship between resiliency and the severity of anxiety were repeatedly confirmed in studies conducted before the pandemic $[27,28]$. Research that took place during the pandemic also emphasized the role of resiliency in counteracting the development of anxiety and the inverse correlation of those psychological characteristics [29-31].

In this study, there was also a slight positive effect of the second component of resiliency - OL on the severity of anxiety. Openness to life experiences may be relevant to experiencing higher emotional tension. Openness can be associated with the search for sensations, connected with the tendency to take risks, and thus with the possibility of feeling emotional tension. Some studies also suggested that the high openness was associated with, e.g., obsessive-compulsive disorders [32]. The observed relationship between OL and anxiety is neither unequivocal nor expected. There are also little reports on this. Therefore, this direction requires further research.

\section{Ego-resiliency and the tendency to use alcohol}

Studies on alcohol consumption during COVID-19 showed an increase in alcohol consumption in various study groups [3,4]. In this study, the relationships linking ER with the tendency to use alcohol proved to be interesting. Ego-resiliency, although weakly, was positively associated with the use of alcohol. One of the components of resiliency, OL, was also positively related to the tendency to use that substance. In the light of the obtained results, it seems that in crisis situations, such as a pandemic, the consumption of alcohol may increase as a substance widely available and used as a way of coping with emotional ten- 
sion. Alcohol may be used provisionally to reduce the level of stress resulting, among others, from concerns for one's health, family and professional future. Openness to life experiences may entail a tendency to take risks, which in turn is positively associated with alcohol use.

The positive relationship between ER and the tendency to use alcohol could be pandemic-specific or might also be a random observation.

Most studies conducted before the pandemic demonstrated the protective role of resiliency in relation to addiction. It was also observed that resiliency was associated with low substance use [33,34]. Research into the relationship between resiliency and the tendency to use alcohol during COVID-19 should be continued.

\section{Ego-resiliency and aggression}

During the SARS-CoV-2 pandemic, an increase in aggressive tendencies has been observed [5]. This study showed a negative correlation between ER and generalized aggression. Moreover, OR was also negatively associated with hostility and anger, and OL with hostility. A resilient, mentally flexible person copes well with crisis and difficult situations, which should counteract excessive development of frustration. In this way, limiting frustration through resilient action may weaken the growth of aggressive tendencies. The development of ER is associated with an increase in optimal psychological regulation, which should facilitate maintaining balance in crisis situations and support good dealing with tensions. The increase in OR may take part in inhibiting aggressive behavior, including its intermediate forms, such as hostility and anger. The nature of ER is not related to aggressive or hostile behavior towards people. Resiliency is associated with good socialization, agreeableness, developing competences in the field of understanding other people, as well as emotional balance $[35,36]$. In previous studies, resiliency has been indicated as a protective factor in relation to aggressive behavior $[37,38]$.
An interesting observation made in this study was a weak, but positive relationship linking ER and its component OR with verbal aggression. It is possible that in the conditions of social isolation and the transfer of a significant part of interpersonal communication to online platforms, verbal aggression has become one of the forms of expressing dissatisfaction. Perhaps during a crisis, it is one of the outlets for the emotional tension accompanying the pandemic.

\section{Differences in respondents' ER}

Differences in terms of ER, which were revealed in the conducted study, were expected. Resiliency is built, among others, based on experience, and its development is favored by the maturity of psychological structures (e.g., identity). It was not surprising, therefore, that its higher intensity was observed in the group of mature people (aged $>29$ years). This age is usually associated with the already well-established belief in oneself, discovering one's own strengths and weaknesses. It is also a period of professionalization and improvement in relation to selected development paths. Older people had the opportunity to experience multiple crises over the course of their lives, allowing them to test and develop a range of effective ways to cope with stress and difficulties. Some research reports also informed about higher resiliency in the elderly $[39,40]$.

In the light of the study, it also seems that a more developed ER might be a feature of people with higher education. The studies play a positive role in developing the personality of students, as well as help build their own professional and personal identity. Tertiary education equips graduates with both specialist and interdisciplinary knowledge, which enriches the scope of possible ways of coping with difficult situations. Graduates are also used to facing various crises related to learning and implementation of studies. Studying provides people with the habit of searching for information, which can support solving various types of problems. 


\section{Research limitations}

The methodology of conducted research caused some phenomena that could have had an impact on the results. Only computer and Internet users had an access to the survey. The data collection method, and more specifically convenience sampling, allows for limited control of the completion of the survey by its participants. The sociodemographic data is based solely on the declarations made by the respondents. The age distribution of the respondents should also be discussed. As $>95 \%$ of the respondents were aged $<50$ years, the obtained results should not be applied to older age groups. Most of the respondents had secondary and higher education, so the observed relationships could characterize groups with a high level of education. Gender distribution should also be taken into account - most of the respondents were women $(>70 \%)$. The obtained results, therefore, mainly refer to well-educated women in middle adulthood who use computers and the Internet. Further research should take into account the extension of the study group in terms of age and education. The group of men should also be better represented.

\section{Summary}

As expected, in the times of the pandemic, ER may be a pro-health property, supporting the maintenance of mental balance. This seems to be especially connected with its negative relationships with anxiety symptoms and aggression. Optimal mental regulation may play an important role in mitigating these unfavorable trends. Age and higher education could also be beneficial for the development of resiliency. The role of OL, as well as the relationship of ER with the tendency to use alcohol in the times of COVID-19 require further research.

\section{CONCLUSIONS}

Ego-resiliency is negatively associated with the intensification of anxiety symptoms and generalized aggression, which suggests its pro-health character in the COVID-19 period.
Optimal regulation, which is one of the components of ER, seems to be particularly beneficial with regard to coping with anxiety and aggression.

Age and higher education may contribute to the development of ER.

The relationship between ER and the tendency to use alcohol during COVID-19 may be positive and requires further observation.

\section{REFERENCES}

1. Salari N, Hosseinian-Far A, Jalali R, Vaisi-Raygani A, Rasoulpoor S, Mohammadi M, et al. Prevalence of stress, anxiety, depression among the general population during the $\mathrm{CO}$ VID-19 pandemic: a systematic review and meta-analysis. Global Health. 2020;16(1):57, https://doi.org/10.1186/s12992020-00589-w.

2. Fullana MA, Hidalgo-Mazzei D, Vieta E, Radua J. Coping behaviors associated with decreased anxiety and depressive symptoms during the COVID-19 pandemic and lockdown. J Affect Disord. 2020;275:80-1, https://doi.org/10.1016/j.jad. 2020.06.027.

3. Ahmed MZ, Ahmed O, Aibao Z, Hanbin S, Siyu L, Ahmad A. Epidemic of COVID-19 in China and associated Psychological Problems. Asian J Psychiatr. 2020;51:102092, https://doi. org/10.1016/j.ajp.2020.102092.

4. Koopmann A, Georgiadou E, Kiefer F, Hillemacher T. Did the General Population in Germany Drink More Alcohol during the COVID-19 Pandemic Lockdown? Alcohol Alcohol. 2020;55(6):698-9, https://doi.org/10.1093/alcalc/agaa058.

5. Mazza M, Marano G, Lai C, Janiri L, Sani G. Danger in danger: Interpersonal violence during COVID-19 quarantine. Psychiatry Res. 2020;289:113046, https://doi.org/10.1016/j. psychres.2020.113046.

6. Menon V, Padhy S, Pattnaik J. Stigma and Aggression Against Health Care Workers in India Amidst COVID-19 Times: Possible Drivers and Mitigation Strategies. Indian J Psychol Med. 2020;42(4):025371762092924, https://doi.org/10.1177/025371 7620929241. 
7. Marčinko D, Jakovljević M, Jakšić N, Bjedov S, Mindoljević Drakulic A. The Importance of Psychodynamic Approach during COVID-19 Pandemic. Psychiatr Danub. 2020;32(1): 15-21, https://doi.org/10.24869/psyd.2020.15.

8. Sygit-Kowalkowska E, Szrajda J, Weber-Rajek M, Porażyński K, Ziółkowski M. Resilience as a predicator of mental health of incarcerated women. Psychiatr Pol. 2017;51(3): 549-60, https://doi.org/10.12740/PP/OnlineFirst/62617.

9. Klohnen EC. Conceptual analysis and measurement of the construct of ego-resiliency. J Pers Soc Psychol. 1996;70(5): 1067-79, https://doi.org/10.1037/0022-3514.70.5.1067.

10. Szwajca K. Resilience and responses to the experience of trauma - a fascinating but difficult study area. Psychiatr Pol. 2014;48(3):563-72.

11. Farkas D, Orosz G. Ego-Resiliency Reloaded: A ThreeComponent Model of General Resiliency. PLoS ONE. 2015; 10(3):e0120883, https://doi.org/10.1371/journal.pone.0120883.

12. Kołodziej-Zaleska A, Przybyła-Basista H. [Ego-resiliency jako zasób osobisty - narzędzie pomiaru i jego wykorzystanie w badaniach interdyscyplinarnych]. Psychol J. 2018;24(1): 159-70. Polish.

13. Letzring TD, Block J, Funder DC. Ego-control and egoresiliency: generalization of self-report scales based on personality descriptions from acquaintances, clinicians, and the self. J Res Pers. 2005;39:395-422, https://doi.org/10.1016/ j.jp.2004.06.003.

14. Jeong YW, Kim JA. A Concept Analysis of Ego-resiliency. Korean J Adult Nurs. 2015;27(6):644-55, https://doi.org/ 10.7475/kjan.2015.27.6.644.

15. Alessandri G, De Longis E, Eisenberg N, Hobfoll SE. A multilevel moderated mediational model of the daily relationships between hassles, exhaustion, ego-resiliency and resulting emotional inertia. J Res Pers. 2020;85:103913, https:// doi.org/10.1016/j.jrp.2020.103913.

16. Kubo T, Sugawara D, Masuyama A. The effect of ego-resiliency and COVID-19-related stress on mental health among the Japanese population. Pers Individ Dif. 2020;175:110702, https://doi.org/10.1016/j.paid.2021.110702.
17. Karaşar B, Canli D. Psychological Resilience and Depression during the Covid-19 Pandemic in Turkey. Psychiatr Danub. 2020;32(2):273-9, https://doi.org/10.24869/psyd.2020.273.

18. Seçer İ, Ulaş S, Karaman-Özlü Z. The Effect of the Fear of COVID-19 on Healthcare Professionals' Psychological Adjustment Skills: Mediating Role of Experiential Avoidance and Psychological Resilience. Front Psychol. 2020;11:561536, https://doi.org/10.3389/fpsyg.2020.561536.

19. Skalski S, Uram P, Dobrakowski P, Kwiatkowska A. The link between ego-resiliency, social support, SARS-CoV-2 anxiety and trauma effects. Polish adaptation of the Coronavirus Anxiety Scale. Pers Individ Dif. 2021;171:110540, https://doi. org/10.1016/j.paid.2020.110540.

20. Satici SA, Kayis AR, Satici B, Griffiths MD, Can G. Resilience, Hope, and Subjective Happiness Among the Turkish Population: Fear of COVID-19 as a Mediator. Int J Ment Health Addiction. 2020, https://doi.org/10.1007/s11469-020-00443-5.

21. Alessandri G, Zuffianò A, Eisenberg N, Pastorelli C. The Role of Ego-Resiliency as Mediator of the Longitudinal Relationship between Family Socio-Economic Status and School Grades. J Youth Adolescence. 2017;46:2157-68, https:/doi. org/10.1007/s10964-017-0691-7.

22. Alessandri G, Eisenberg N, Vecchione M, Caprara GV, Milioni M. Ego-resiliency development from late adolescence to emerging adulthood: A ten-year longitudinal study, J Adolesc. 2016;50:91-102, https://doi.org/10.1016/j.adolescence. 2016.05.004.

23. Syed M, Eriksson PL, Frisén A, Hwang CP, Lamb ME. Personality development from age 2 to 33: Stability and change in ego resiliency and ego control and associations with adult adaptation. Dev Psychol. 2020;56(4):815-32, https://doi.org/ 10.1037/dev0000895.

24. Spitzer RL, Kroenke K, Williams JB, Löwe B. A brief measure for assessing generalized anxiety disorder: the GAD-7. Arch Intern Med. 2006;166(10):1092-7, https://jamanetwork. com/journals/jamainternalmedicine/fullarticle/410326.

25. Saunders JB, Aasland OG, Babor TF, de la Fuente JR, Grant M. Development of the Alcohol Use Disorders Identification Test 
(AUDIT): WHO Collaborative Project on Early Detection of Persons with Harmful Alcohol Consumption-II. Addiction. 1993;88(6):791-804, https://doi.org/10.1111/j.1360-0443.1993. tb02093.x.

26. Buss AH, Perry M. The aggression questionnaire. J Pers Soc Psychol. 1992;63(3):452-9, https://doi.org/10.1037/00223514.63.3.452.

27. Cleary M, Kornhaber R, Thapa DK, West S, Visentin D. The effectiveness of interventions to improve resilience among health professionals: A systematic review. Nurse Educ Today. 2018;71:247-63, https://doi.org/10.1016/j.nedt. 2018.10.002.

28. Lukow HR 2nd, Godwin EE, Marwitz JH, Mills A, Hsu NH, Kreutzer JS. Relationship Between Resilience, Adjustment, and Psychological Functioning After Traumatic Brain Injury: A Preliminary Report. J Head Trauma Rehabil. 2015;30(4): 241-8, https://doi.org/10.1097/HTR.0000000000000137.

29. Zhang J, Yang Z, Wang X, Li J, Dong L, Wang F, et al. The relationship between resilience, anxiety and depression among patients with mild symptoms of COVID-19 in China: A cross-sectional study. J Clin Nurs. 2020;29(21-22):4020-9, https://doi.org/10.1111/jocn.15425.

30. Barzilay R, Moore T, Greenberg D, DiDomenico G, Brown L, White L, et al. Resilience, COVID-19-related stress, anxiety and depression during the pandemic in a large population enriched for healthcare providers. Transl Psychiatry. 2020;10:291, https://doi.org/10.1038/s41398-02000982-4.

31. Luceño-Moreno L, Talavera-Velasco B, García-Albuerne Y, Martín-García J. Symptoms of Posttraumatic Stress, Anxiety, Depression, Levels of Resilience and Burnout in Spanish Health Personnel during the COVID-19 Pandemic. Int J Environ Res Public Health. 2020;17(15):5514, https://doi. org/10.3390/ijerph17155514.
32. Bienvenu OJ, Samuels JF, Costa PT, Reti IM, Eaton WW, Nestadt G. Anxiety and depressive disorders and the fivefactor model of personality: a higher- and lower-order personality trait investigation in a community sample. Depress Anxiety. 2004;20(2):92-7, https://doi.org/10.1002/da.20026.

33. Green KT, Beckham JC, Youssef N, Elbogen EB. Alcohol misuse and psychological resilience among U.S. Iraq and Afghanistan era veterans. Addict Behav. 2014;39(2):406-13, https://doi.org/10.1016/j.addbeh.2013.08.024.

34. Bartone PT, Hystad SW, Eid J, Brevik JI. Psychological hardiness and coping style as risk/resilience factors for alcohol abuse. Mil Med. 2012;177(5):517-24, https://doi.org/10.7205/ MILMED-D-11-00200.

35. Kinman G, Grant L. Exploring stress resilience in trainee social workers: the role of emotional and social competencies. Br J Soc Work. 2011;41(2):261-75, https://doi.org/10.1093/ bjsw/bcq088.

36. Semmer N. Personality, stress and coping. In: Vollrath M, editor. Handbook of personality and health. Chichester: Wiley; 2006. p. 73-113.

37. Sharma MK, Marimuthu P. Prevalence and psychosocial factors of aggression among youth. Indian J Psychol Med. 2014;36(1):48-53, https://doi.org/10.4103/0253-7176.127249.

38. Zaharakis NM, Mason MJ, Brown A, Moore M, Garcia C, Foster R, et al. Resiliency Moderates the Influence of Somatization on Externalizing Problems. J Child Fam Stud. 2018;27:2978-89, https://doi.org/10.1007/s10826-018-1141-1.

39. Gooding PA, Hurst A, Johnson J, Tarrier N. Psychological resilience in young and older adults. Int J Geriatr Psychiatry. 2012;27(3):262-70, https://doi.org/10.1002/gps.2712.

40. MacLeod S, Musich S, Hawkins K, Alsgaard K, Wicker ER. The impact of resilience among older adults. Geriatr Nurs. 2016;37(4):266-72, https://doi.org/10.1016/j.gerinurse.2016. 02.014 .

This work is available in Open Access model and licensed under a Creative Commons Attribution-NonCommercial 3.0 Poland License - http://creativecommons.org/ licenses/by-nc/3.0/pl/deed.en. 